\title{
A systematic review and quantitative analysis of resting energy expenditure prediction equations in healthy overweight and obese children and adolescents
}

\section{Authors:}

Lucy Chima $^{1}$, Hilda M Mulrooney ${ }^{2}$, Janet Warren ${ }^{3}$, Angela M Madden ${ }^{1}$

Work undertaken in:

School of Life and Medical Sciences, University of Hertfordshire, Hatfield AL10 9AB.

\section{Affiliations:}

${ }^{1}$ School of Life and Medical Sciences, University of Hertfordshire, Hatfield, AL10 9AB, UK.

${ }^{2}$ School of Life Sciences, Pharmacy \& Chemistry, Faculty of Science, Engineering and Computing, University of Kingston, Kingston Upon Thames KT1 2EE, UK.

${ }^{3}$ Firststop Nutrition Limited, Lyford, Oxfordshire OX12 0EE, UK.

\section{Corresponding author:}

Dr Angela Madden, School of Life and Medical Sciences, University of Hertfordshire, Hatfield AL10 9AB; telephone 01707 281385; email a.madden@herts.ac.uk

Specific role / authorship of all authors:

Lucy Chima undertook the database searches, data extraction and analysis and contributed to the manuscript.

Hilda Mulrooney co-designed the study, undertook data extraction and analysis and contributed to the manuscript.

Janet Warren suggested the original idea, advised on aspects relating to paediatric nutrition and contributed to the manuscript.

Angela Madden co-designed and supervised the overall study, duplicated the searches and contributed to data analysis and writing of the manuscript.

\section{Conflict of interest:}

Each of the authors declares that they have no conflicts of interest. 
Funding statement:

A Rank Prize Funds vacation studentship was used to support Lucy Chima in the early stage of the study. Additional support was provided by the University of Hertfordshire through quality-related research funding.

\section{Acknowledgements}

The authors thank authors who responded to requests for additional data: Professor Stefano Lazzer, Dr Peter Weijs, Dr Silvia Faria, Dr Mario Siervo \& Professor Alessandro Sartorio. 


\section{Abstract}

Background: Resting energy expenditure (REE) estimates are often needed in young people and can be predicted using prediction equations based on body weight. However, these equations may perform poorly in obesity and overweight. The aim of this systematic review was to identify equations based on simple anthropometric and demographic variables which provide the most accurate and precise estimates of REE in healthy obese and overweight young people.

Methodology: Systematic searches for relevant studies in healthy obese and overweight young people aged $\leq 18$ years were undertaken using PubMed, Scopus, Cinahl, OpenGrey and Cochrane Library (completed January 2018). Search terms included metabolism, calorimetry, obesity and prediction equation. Data extraction, study appraisal and synthesis followed PRISMA guidelines. Results: From 390 screened titles, 13 studies met inclusion criteria. The most accurate REE predictions (least biased) were provided by Schofield equations (+0.8\% [3-18 years]; 0\% [11-18 years]; $+1.1 \%$ [3-10 years]). The most precise REE estimations (percentage of predictions $\pm 10 \%$ of measured) for 11-18 years were provided by Mifflin equations (62\%), and for 7-18 years by the equations of Schmelzle (57\%), Henry (56\%) and Harris Benedict (54\%). Precision of Schofield predictions was $43 \%$ in both age groups. No accuracy data were available for those $<3$ years or for precision for those $<7$ years.

Principal conclusions: No single equation provided accurate and precise REE estimations in this population. Schofield equations provided the most accurate REE predictions so are useful for groups. Mifflin equations provided the most precise estimates for individuals aged 11-18 but tended to underestimate REE. 


\section{Introduction}

Excess weight in children continues to be a major public health problem globally ${ }^{(1)}$ and in the UK. According to the latest National Child Measurement Programme (NCMP), which measures weight and height of children at school, $12.8 \%$ of $4-5$ year olds and $14.2 \%$ of $10-11$ year olds in England are overweight and $9.5 \%$ and $20.1 \%$ respectively are obese ${ }^{(2)}$. Excess weight is not evenly distributed among children; obesity prevalence is higher in boys than girls in both age groups, and highest in black children compared with other ethnicities. It is also socially patterned, with prevalence rates double in the most deprived compared with the least deprived children ${ }^{(2,3)}$. This is of concern since excess weight in children is highly visible and with implications for poorer physical and mental health ${ }^{(4)}$ and reduced educational attainment ${ }^{(5-7)}$. Additionally, childhood and especially adolescent obesity tracks strongly into adulthood ${ }^{(7,8-10,11)}$. The negative health impacts of excess weight in adulthood have been well documented including increased risk of type 2 diabetes, some cancers, non-alcoholic fatty liver disease, musculoskeletal disorders and cardiovascular disease as well as poorer mental health ${ }^{(9,12)}$. It follows therefore that tackling excess weight in children is beneficial for their long-term health prospects ${ }^{(7)}$.

Current guidance on weight management in childhood recommends that children should reduce weight gain if they are still gaining height ${ }^{(13,14)}$. For those who have achieved their full height, weight loss will be required to achieve healthy weight status ${ }^{(13,14)}$. This depends on the child and family's ability to support the long-term changes to behaviour required to achieve and maintain weight $\operatorname{loss}{ }^{(9,11,13-14)}$. Quantity and rate of target weight loss are clinical decisions ${ }^{(9)}$; dependent on those decisions and the child's current energy intake and expenditure, personalised weight loss plans should be developed, tailored to the individual ${ }^{(13)}$. To achieve weight loss an energy deficit will be required ${ }^{(15)}$. A starting point for determining the deficit is estimating total energy expenditure (TEE).

TEE is the amount of energy used daily by individuals ${ }^{(16)}$, of which approximately $60-70 \%$ is basal metabolic rate $(\mathrm{BMR})^{(17,18)}$. TEE is difficult and expensive to measure and may be estimated from BMR using the factorial method to include contributions from dietary induced thermogenesis and activity $^{(19)}$. As measurement of true BMR is unfeasible ${ }^{(20)}$, the term resting energy expenditure (REE) is used throughout this review and refers to estimated BMR. The 'gold standard' for REE measurement is indirect calorimetry (IC), in which oxygen consumption $\left(\mathrm{VO}_{2}\right)$ and carbon dioxide production $\left(\mathrm{VCO}_{2}\right)$ are measured with appropriately calibrated and validated equipment (e.g. 
metabolic cart) under controlled conditions ${ }^{(20)}$ and used to calculate $\operatorname{REE}^{(21)}$. Requisite equipment is bulky, costly, and requires external calibration and training for proper use. Inexpensive, lightweight, uncalibrated devices (e.g. handheld indirect calorimeters) usually rely on measurement of $\mathrm{VO}_{2}$ only, make assumptions regarding substrate metabolism and lack consistent validation ${ }^{(22)}$. In order to estimate REE without the need for IC, a number of predictive energy expenditure equations have been developed, and are used widely ${ }^{(23)}$. Many are complex, requiring access to measurements not usually available in standard clinical settings (e.g. fat free mass, organ weights). Single equations have been proposed ${ }^{(23,24)}$ or, more commonly, multiple age or sex specific variants ${ }^{(25,26)}$. At a given weight, individual REE depends largely on body composition with fat free mass (FFM) exhibiting greater metabolic activity than fat mass $(\mathrm{FM})^{(27)}$. In obesity, $\mathrm{FM}$ increases more than $\mathrm{FFM}^{(28)}$, so REE increase is not directly proportional to weight gain. Additionally, body composition at any weight has altered over two generations to favour a higher proportion of $\mathrm{FM}^{(29)}$. Historic prediction equations derived from populations with lower prevalence of overweight and obesity, or in lean subjects who are not overweight or obese may lead to inaccurate estimation of $\mathrm{TEE}^{(30-32)}$ in this population. In different scenarios, overestimation of REE may fail to impose the level of caloric restriction required to achieve negative energy balance. Underestimation may frustrate weight management by imposing inappropriate and unsustainable dietary restrictions. Importantly, over restriction in children may also adversely affect their growth and nutritional status ${ }^{(33)}$.

In current clinical practice, simple weight-based equations or estimated average requirements are used to estimate energy requirements regardless of adiposity ${ }^{(34,35)}$. Many different equations have been published but selecting the most appropriate predictive equation will help to avoid either over or underestimation of energy requirements when developing a tailored plan ${ }^{(36)}$. While a previous systematic review examined the accuracy and precision of REE prediction equations in overweight and obese adults ${ }^{(37)}$, there is no consensus about which equation/s are most appropriate for accurate estimation of REE in children ${ }^{(38,39)}$. Therefore, the aim of this systematic review was to determine which prediction equations based on simple anthropometric and demographic variables provide the most accurate (closeness to measured energy expenditure) and precise (proportion of participants with predicted values within $10 \%$ of measured) estimates of REE in healthy overweight and obese young people aged 1-18 years. 


\section{Materials and Methods}

A systematic review of the published literature was undertaken in accordance with the Preferred Reporting Items for Systematic Review and Meta-Analysis (PRISMA) guidance ${ }^{(40)}$. Details of the protocol were registered with the PROSPERO International Prospective Register of Systematic Reviews $^{(41)}$.

\section{Search Strategy}

Boolean searches for published studies were undertaken by two researchers within the electronic databases PubMed, Scopus, Cinahl, OpenGrey and the Cochrane Library using the key words (basal metabolism OR calorimetry) AND (obesity OR overweight) AND (prediction equation OR predictive equation). MESH terms were used within PubMed for all key words except prediction equation and predictive equation. To prevent exclusion of relevant studies, no further search limits were applied. No studies were excluded on the basis of language; all studies were published in English or reliable translations were available. Publications for all dates until 15 January 2018 were searched. All types of study design were included. Additional primary studies were identified by manually searching the reference lists of review articles.

\section{Screening, inclusion \& exclusion criteria}

Published studies identified in the search were evaluated independently by two researchers initially using titles and abstracts. On the basis of the screening, studies were identified as either 'excluded' or 'full text assessed for eligibility'. Papers which provided original research data comparing predicted energy expenditure (pREE) calculated using a prediction equation with energy expenditure measured using IC (mREE) were extracted. Studies were included if they utilised prediction equations which were based on variables easily measured in clinical or public health practice (e.g. height, weight, waist circumference, age, sex); equations based on more complex variables not generally available in clinical practice (e.g. fat-free mass, organ weight) were excluded. Studies which used recognised diagnostic criteria for identifying overweight and obesity in children, e.g. using appropriate centiles, were included, and excluded if they did not. Studies were excluded if study populations did not include overweight or obese participants, or if overweight or obese participants were included but not reported separately. Studies were excluded if study participants were not aged 1-18 years. 
Studies were included if participants were stated to be in good health or free from illness and disease but excluded if they were described as being acutely ill, having a chronic condition that might influence metabolic rate, taking medication that might have this effect, or if this was not clear from the methods described. The validity of the method of measuring energy expenditure was also considered. Studies were included if an externally calibrated indirect calorimeter measuring $\mathrm{VO}_{2}$ and $\mathrm{VCO}_{2}$ was used. Studies using uncalibrated devices were excluded. Studies were excluded if participants were asleep or active during REE measurement, or if they had not fasted for a minimum of 6 hours beforehand. The reference lists of papers identified as reviews or meta-analysis studies were examined for additional sources, which were then screened using the approach described above.

\section{Extraction of data}

Papers which met the inclusion criteria were examined by two researchers. Data were extracted into a specifically prepared form and included study population, context of study and method of REE measurement. A table of equations based on simple variables evaluated by included studies was compiled from the original publications. Papers were critically evaluated using primary summary measures for each of the prediction equations reported: (1) accuracy (i.e. predicted energy expenditure expressed as a percentage of the measured energy expenditure or in a format where this could be calculated) and (2) precision (i.e. percentage of participants with predicted energy expenditure within $10 \%$ of measured values). To facilitate calculation of these data, equations were excluded from the analysis if they were evaluated by fewer than two studies. Studies reported data for whole populations, age-based subgroups, male/female subgroups, or a combination of these. Where reporting for multiple subgroups led to duplicate reporting of participant data, age-based subgroups were prioritised for analysis and data for alternative subgroup divisions were removed. Most studies applied age specific variants of equations as appropriate to the individual participant. The intention was to include data for 1-18 years. Since none of the papers which met the criteria for this review included data for 1-2 years, data were analysed for the whole population of 3-18 year and separately for 11-18 years and 3-10 years subgroups with the age ranges determined pragmatically from the data in the included studies and with regard to puberty which impacts on body composition and thus energy expenditure. In each group, data were analysed by study subgroup and by participant to give mean precision and accuracy for each equation. Data from all categories of overweight and obesity were considered together in the analyses because there were insufficient to separate into meaningful subgroups of excess body weight. The data were extracted and the findings synthesised manually to allow for analysis by participant as well as by study. Data 
from $50 \%$ of participants in the accuracy analysis and $68 \%$ of those in the precision analysis came from one study centre in Northern Italy ${ }^{(23,42-43)}$. Analyses were repeated with and without these data to investigate their potential influence on the overall results. Where any clarification was needed to determine inclusion of data, authors of original papers which met the inclusion criteria were contacted. Stages 2 and 3 of the ROBIS tool ${ }^{(44)}$ were used to assess risk of bias in the present systematic review; the optional stage 1 was omitted because evaluating prediction equations falls outside the four PICO questions included in this tool. 


\section{Results}

The searches identified 390 possible studies; after exclusion of duplicates, 246 papers were initially screened of which 166 were excluded. Eighty full-text papers were assessed for eligibility, of which 67 were excluded. Thirteen studies ${ }^{(23,39,42-43,45-53)}$ met the criteria for inclusion in the systematic review (Figure 1). Characteristics of studies included are shown in Table 1. Studies included evaluated a total of 14 individual or groups of REE prediction equations in populations from seven countries in Europe and North America (Table 2).

The accuracy of predictions was reported by studies comprising between 121 and 2636 participants with smaller study populations in younger children (3-10 years). Accuracy in all age groups varied with mean bias ranging from an underestimation of $14.0 \%$ to an overestimation of $11.6 \%$ compared to measured values (Table 3). Considering analysis by individual participants, the least mean bias was observed in the predictions derived using the equations of Schofield ${ }^{(25)}$ in all age groups: $+0.8 \%$ (3-18 years); $0 \%$ (11-18 years); $+1.1 \%$ (3-10 years). The predictions from the $\mathrm{WHO}^{(26)}$ equations based on weight and height also provided values with low mean bias but these have not been evaluated in younger children: $+0.8 \%$ (3-18 years); $+1.1 \%$ (11-18 years). When results were examined by studies, the same equations provided least mean bias: Schofield $+0.4 \%$ (3-18 years); $+0.5 \%$ (11-18 years); $0 \%$ (3-10 years) and WHO weight and height $+1.3 \%$ (3-18 years); $-0.3 \%$ (1118 years). The $\mathrm{WHO}^{(26)}$ equations based solely on weight provided less accurate mean predicted REE values with a tendency to overestimate by $>8 \%$.

The precision of predicted values was reported by studies comprising between 226 and 1759 participants. There were insufficient data to report on children aged $<7$ years. Precision also varied with the proportion of predicted values within $10 \%$ of measured REE varying between $28-63 \%$ (Table 4). The highest precision in the 11-18 years group was observed using the equations of $\operatorname{Mifflin}^{(38)}$ (62\% of individual observations) whilst Schofield and WHO weight and height provided estimates within $10 \%$ of measured values with $43 \%$ and $45 \%$ of individual observations; values for analysis by studies were similar. In the 7-18 years group, the highest precision was observed using the equations of Schmelzle ${ }^{(52)}$, Harris Benedict ${ }^{(54)}$ and Henry ${ }^{(55)}(57 \%, 54 \%$ and $56 \%$ of individual observations) compared to $43 \%$ and $44 \%$ from Schofield and WHO weight and height; again, values for analysis by studies were similar.

Removing the large datasets from the single study centre in Northern Italy ${ }^{(23,42-43)}$ had no impact on the observations of accuracy but resulted in the Mifflin equations giving the most precise estimates in the 7-18 group (62\%-63\%) (see supplementary data). 
The assessed risk of bias of this review was considered to be low when evaluated using the ROBIS $^{(44)}$ tool (Supplementary data). 


\section{Discussion}

The aims of this systematic review were to identify the prediction equations based on simple anthropometric and demographic variables that provide the most accurate and precise estimates of REE in healthy overweight and obese young people aged 1-18 years. Data from studies that met the inclusion criteria indicate that at a population level, the most accurate equations for 11-18 years are those of Schofield ${ }^{(25)}$ and $\mathrm{WHO}^{(26)}$ based on weight and height as they showed minimal bias. The equations of Schofield also provided the most accurate predictions for children aged 3-10 years. Whilst the accuracy of the Schofield and WHO weight and height equations for children aged 3-18 years provide useful guidance for those working with groups of young people, those working with individuals will be equally interested in the precision data and this is less reliable. Less than $50 \%$ of REE predictions derived using the Schofield and WHO weight and height were within $10 \%$ of measured values regardless of age group or whether analysed per participant or per study. The best precision in 11-18 years olds was observed with the Mifflin ${ }^{(38)}$ equations and this finding is comparable to that of a systematic review undertaken in adults ${ }^{(37)}$ which is surprising as these equations were derived in a population aged 19-78 years. A possible explanation for this is that although the Mifflin equations ${ }^{(38)}$ were derived from an adult population with a mean age of 45 years, their participants were stratified by age and comprised approximately $20 \%$ aged $\leq 29$ years. In addition, approximately $47 \%$ of their participants weighed $\geq 120 \%$ of ideal body weight compared to just $16 \%$ weighing $<100 \%$. It is possible that the better precision observed using the Mifflin equations in those aged 11-18 years in the present analysis reflects these participants being potentially post-pubertal and, therefore, closer in body composition to the Mifflin adults than when the wider age group of 7-18 years was considered. In this study if a wider age group of 7-18 years were considered, the equations of Schmelzle ${ }^{(52)}$, Harris Benedict ${ }^{(54)}$ and Henry ${ }^{(55)}$ all performed with comparable precision. However, with increased precision, accuracy is compromised so practitioners who need estimations of REE should consider what is important for their situation when selecting an equation and be aware that no equations provide accurate and precise predictions in all groups and it is not realistic to expect this.

There are a number of challenges associated with investigating the prediction of REE in young people. These include the dynamic changes occurring in relation to growth and variation in body composition and the effects of puberty ${ }^{(61)}$ in those aged 11-18 years as explained above. Obesity has been reported to increase the likelihood of early onset of puberty in girls with less clarity about its' impact on boys ${ }^{(62,63)}$. In addition, differences in physical activity levels between children and adolescents may impact upon body composition and thus influence REE. Physical activity levels are generally low in UK children and boys are more active than girls (23\% of boys and $20 \%$ of girls 
met the recommendations ${ }^{(64)}$ for physical activity in $\left.2015^{(65)}\right)$. Activity levels in girls fall with age, while hours spent in sedentary activities increase with age ${ }^{(66)}$. In addition, obese children are likely to be less active than non-obese ${ }^{(67-70)}$. Physical activity has been shown to affect anthropometric measurements with differential effects by sex; in girls apart from BMI, all anthropometric measures were affected while in boys BMI z-score and fat free mass only were affected ${ }^{(71)}$. The possible effects of physical activity are separate from but related to the effects of puberty, but may help to explain why REE prediction equations perform less well than might be expected. The equations examined in the included studies do not take these factors into account and this may contribute to the lower levels of precision observed in children in the present review compared to adults ${ }^{(37)}$.

There was insufficient information to evaluate the accuracy of equations in children aged $<3$ years or of precision of equations in those $<7$ years. As there is increasing awareness of the risks of overweight and obesity in very young children ${ }^{(72)}$, more research is needed in this age group to provide guidance about their energy requirements. There are methodological complexities associated with measuring REE using indirect calorimetry in younger children ${ }^{(73)}$ and where this has been undertaken, it is primarily in those who are critically ill and where respiratory gases are being monitored for clinical purposes ${ }^{(74)}$ as well as of interest for determining energy requirements. In addition, different criteria for identifying overweight and obesity are used in very young children than those who are older ${ }^{(75,76)}$ which adds further complexity as a child grows and transitions from one to the other.

Based on the numbers in Table 3, it appears that equations which have been widely tested tend to have better accuracy (with the exception of the WHO (wt) equation). Older equations perform better and this may reflect the fact that they have been tested more and in more diverse populations than newer equations. The exception of the WHO (wt) equation may reflect the fact that this equation relies on a single parameter (body weight) which does not adequately reflect the complexities of different body composition in this group. A single body weight may reflect a range of different body compositions, and the relative proportions of fat and fat-free mass will impact upon REE. Several studies have developed new equations in a calibration population and tested them in a separate validation group and recommended their use over previously published equations ${ }^{(39,45)}$. This is perhaps unsurprising as participants for calibration and validation were commonly recruited from the same population. However, to minimise the potential impact of this on the conclusions, this review excluded equations that had been evaluated in less than two studies. 


\section{Strengths}

The eligibility criteria of the review were used to ensure the studies included provided high quality data. The protocol was published in advance and adhered to throughout ${ }^{(41)}$. All decisions were made in duplicate and a third author was consulted on the few occasions when they did not agree. The review team included researchers with experience of undertaking systematic reviews, measuring REE and using REE prediction in clinical paediatric practice so collectively were able to evaluate a range of relevant aspects. The risk of bias of the review was assessed using the ROBIS tool $^{(44)}$ and indicated that robust mechanisms were used throughout and where methods deviated from the published protocol, full explanations were given. Risk of bias was deemed to be low.

\section{Limitations}

A range of definitions of obesity were accepted, providing these were explicitly stated, and included different cut offs for percentiles of normal data or relative values, e.g. $\%$ ideal body weight. This variation between studies means that degree of excess weight was not explored (i.e. as in adults using simply BMI categories to define overweight and obesity). It is likely that different degrees of excess body weight impact differently on total REE and REE per kg body weight but it was not possible to take this into account. The 13 studies included in the data analysis were undertaken in Europe (nine) and North America (four). This means that large sections of the world's population have not been represented. Studies from other continents were retrieved by the search strategy but were subsequently excluded due to not meeting inclusion criteria including methodology which may have impacted on the results, e.g. fasting for $<6$ hours and REE not measured using externally calibrated indirect calorimeter ${ }^{(77,78)}$. This geographical limitation is important because ethnicity is known to impact on REE through differences in body composition and the review has not been able to address this. McDuffie et al. ${ }^{(79)}$ reported on the impact on ethnicity in Black and White overweight and normal weight children but did not meet inclusion criteria for the review, as data for overweight and obese children was not reported separately.

\section{Conclusions}

No single equation provided both accurate and precise REE estimations in this population and it is important to recognise that all calculated values are just estimates. The Schofield equations provided the most accurate REE predictions so are recommended for those working with groups of overweight or obese young people aged 3-18 years where, collectively, a least biased REE value is 
required. However, the Schofield equations are not optimum for those seeking a precise REE value for individuals as only $43 \%$ of predictions are likely be within $10 \%$ of measured REE.

In clinical practice, where precision is often more important than accuracy, the Mifflin equations are recommended for estimating REE in young people aged 11-18 years. However, practitioners should be aware that these equations, while the most precise in this age group, are imprecise in approximately $40 \%$ of individuals and tend to provide underestimates of REE. Although the Mifflin equations did not provide the most precise estimations of REE in the wider age group of 718 years, they are recommended in preference to those of Henry ${ }^{(56)}$ which currently form the basis of the UK Dietary Reference Values for Energy ${ }^{(35)}$ but which demonstrated poor precision in those who are overweight or obese.

Further studies of prediction of REE are required in children under 7 years, and particularly in those aged $<3$ years, to enable recommendations to be made in these groups. 


\section{Transparency declaration}

The lead author affirms that this manuscript is an honest, accurate, and transparent account of the study being reported. The reporting is compliant with the PRISMA guidelines. The lead author affirms that no important aspects of the study have been omitted and that any discrepancies from the study as planned in the published protocol (PROSPERO 2016 CRD42016042790) have been explained. 


\section{References}

1. UNICEF, World Health Organization \& World Bank Group Joint Child Malnutrition Estimates (2017). Levels and Trends in Child Malnutrition.

http://www.who.int/nutgrowthdb/jme_brochoure2017.pdf (accessed January 2018).

2. NHS Digital (2017) National Child Measurement Programme England, 2017/18 school year. https://digital.nhs.uk/data-and-information/publications/statistical/national-child-measurementprogramme/2017-18-school-year (accessed February 2019)

3. Weichselbaum E \& Buttriss JL. Diet, nutrition \& schoolchildren: an update. Nutr Bull. 2014; 39: $9-73$.

4. Lobstein T \& Jackson-Leach R. Estimated burden of paediatric obesity and co-morbidities in Europe. Part 2. Numbers of children with indicators of obesity-related disease. Int J Pediatr Obes. 2006;1: 33-41.

5. Pizzi MA \& Vroman K. Childhood obesity: effects on children's participation, mental health, and psychosocial development. Occup Ther Health Care. 2013;27: 99-112.

6. Miller AL, Lee HJ \& Lumeng JC. Obesity-associated biomarkers and executive function in children. Pediatr Res. 2015;77: 143-7.

7. World Health Organisation (2016) Report of the Commission on Ending Childhood Obesity. http://apps.who.int/iris/bitstream/handle/10665/204176/9789241510066_eng.pdf;jsessionid=C6F50 1D4ACBCE714C36D2DB840167B62? sequence=1 (accessed July 2018)

8. Nader PR, O’Brien M, Houts R et al. Identifying risk for obesity in early childhood. Pediatrics. 2006;118: e594-e601.

9. Scottish Intercollegiate Guidelines Network (2010) Management of obesity. A national clinical guideline [115]. http://www.sign.ac.uk/assets/sign115.pdf (accessed July 2018)

10. Litwin SE. Childhood Obesity and Adulthood Cardiovascular Disease: Quantifying the Lifetime Cumulative Burden of Cardiovascular Risk Factors. J Am Coll Cardiol. 2014;64: 1588-90.

11. Barlow SE. Expert committee recommendations regarding the prevention, assessment, and treatment of child and adolescent overweight and obesity: summary report. Pediatrics 2007;120: S164-92. 
12. Health and Social Care Information Centre (2018) Health Survey for England 2017. Adult and child overweight and obesity. http://healthsurvey.hscic.gov.uk/media/78619/HSE17-Adult-ChildBMI-rep.pdf (accessed March 2019)

13. National Institute for Health and Care Excellence (2013) Weight management: lifestyle services for overweight or obese children and young people. Public Health guidance [PH47].

https://www.nice.org.uk/guidance/ph47 (accessed July 2018)

14. National Institute for Health and Care Excellence (2014) Obesity: identification, assessment and management. Clinical Guideline [CG189]. https://www.nice.org.uk/guidance/cg189 (accessed July 2018)

15. Butland B, Jebb S, Kopelman P et al. Tackling Obesities: Future Choices - Project Report, 2nd edn. London: Foresight; 2007.

16. Henes ST, Cummings DM, Hickner RC et al. Comparison of predictive equations and measured resting energy expenditure among obese youth attending a pediatric healthy weight clinic: one size does not fit all. Nutr Clin Pract. 2013;28: 617-24.

17. Wiskin A, Davies J, Wootton S et al. Energy expenditure, nutrition and growth. Arch Dis Child 2011;96: 567-72.

18. Mellecker RR \& McManus AM. Measurement of resting energy expenditure in healthy children. J Parent Enteral Nutr 2009;33: 640-45.

19. Levine JA. Measurement of energy expenditure. Public Health Nutr. 2005;8: 1123-1132.

20. Haugen HA, Chan L \& Li F. Indirect calorimetry: A practical guide for clinicians. Nutr Clin Pract. 2007;22: 377-388.

21. Weir JB de V. New methods for calculating metabolic rate with special reference to protein metabolism. J Physiol. 1949;109: 1-9.

22. Hipskind P, Glass C, Charlton D et al. Do handheld calorimeters have a role in assessment of nutrition needs in hospitalized patients? A systematic review of literature. Nutr Clin Pract. 2011;26: 426-433.

23. Lazzer S, Agosti F, De Col A et al. Development and cross-validation of predictive equations for estimating resting energy expenditure in severely obese Caucasian children and adolescents. $\mathrm{Br}$ J Nutr. 2006; 96: 973-79. 
24. Müller M, Bosy-Westphal A, Klaus S. et al. World Health Organization equations have shortcomings for predicting resting energy expenditure in persons from a modern, affluent population: Generation of a new reference standard from a retrospective analysis of a German database of resting energy expenditure. Am J Clin Nutr. 2004; 80:1379-1390.

25. Schofield WN. Predicting basal metabolic rate, new standards and review of previous work. Hum Nutr Clin Nutr. 1985; 39: 5-41.

26. World Health Organization. Energy and protein requirements. Report of a joint FAO/WHO/UNU expert consultation. Geneva: World Health Organization; 1985.

27. Garby L, Garrow JS, Jorgensen B et al. Relation between energy expenditure and body composition in man: Specific energy expenditure in vivo of fat and fat-free tissue. Eur J Clin Nutr.1988; 42: 301-305.

28. Hall KD. Body fat and fat-free mass inter-relationships: Forbes's theory revisited. Br J Nutr. 2007;97: 1059-1063.

29. Tanamas SK, Lean MEJ, Combet E et al. Changing guards: Time to move beyond body mass index for population monitoring of excess adiposity. QJM. 2016; 109: 443-446.

30. Horgan GW \& Stubbs J. Predicting basal metabolic rate in the obese is difficult. Eur J Clin Nutr. 2003; 57: 335-340.

31. Lof M, Hannestad U \& Forsum E. Comparison of commonly used procedures, including the doubly-labelled water technique, in the estimation of total energy expenditure of women with special reference to the significance of body fatness. Br J Nutr. 2003; 90: 961-968.

32. Amaro-Gahete FJ, Sanchez-Delgado G, Alcantara JMA et al. Congruent validity of resting energy expenditure predictive equations in young adults. Nutrients 2019; 11: 223.

33. Stewart L. Obesity. In: Clinical Paediatric Dietetics. pp. 798-808 [V. Shaw, editor]. Somerset: Wiley; 2014.

34. Shaw V \& McCarthy H. Nutritional assessment, dietary requirements, feed supplementation. In: Clinical Paediatric Dietetics. pp. 3-22 [V. Shaw, editor]. Somerset: Wiley; 2014.

35. Scientific Advisory Committee on Nutrition. Dietary Reference Values for Energy. London: TSO; 2011.

36. Chan DFY, Li AM, Chan MHM et al. Validation of prediction equations for estimating resting energy expenditure in obese Chinese children. Asian Pac J Clin Nutr. 2009; 18: 251-6. 
37. Madden AM, Mulrooney HM \& Shah S. Estimation of energy expenditure using prediction equations in overweight and obese adults: A systematic review. J Hum Nutr Diet. 2016; 29: 458476.

38. Mifflin MD, St Jeor ST, Hill LA et al. A new predictive equation for resting energy expenditure in healthy individuals. Am J Clin Nutr. 1990; 51: 241-47.

39. Tverskaya R, Rising R, Brown $\mathrm{D}$ et al. Comparison of several equations and derivation of a new equation for calculating basal metabolic rate in obese children. J Am Coll Nutr.1998; 17: 333-36.

40. Moher D, Liberati A, Tetzlaff J, et al. Preferred Reporting Items for Systematic Reviews and Meta-Analyses: The PRISMA Statement. PLoS Med. 2009; 6: e1000097. doi:10.1371/journal.pmed1000097

41. Madden A, Chima L, Mulrooney H et al. (2016). A systematic review of resting energy expenditure prediction equations in healthy overweight and obese children and adolescents. Retrieved March 12, 2019 from http://www.crd.york.ac.uk/PROSPERO/display_record.php?ID=CRD42016042790

42. Lazzer S, Agosti F, De Col A et al. Comparison of predictive equations for resting energy expenditure in severely obese Caucasian children and adolescents. J Endocrinol Invest. 2007; 30: 313-317.

43. Lazzer S, Bedogni G, Lafortuna $\mathrm{C}$ et al. Relationship between basal metabolic rate, gender, age and body composition in 8,780 White Obese Subjects. Obesity (Silver Spring). 2010; 18: 71-78. 44. Whiting P, Savović J, Higgins JPT et al. ROBIS: A new tool to assess risk of bias in systematic reviews was developed. J Clin Epidemiol. 2016; 69: 225-234.

45. Derumeaux-Burel H, Meyer M, Morin L et al. Prediction of resting energy expenditure in a large population of obese children. Am J Clin Nutr. 2004; 80: 1544-1550.

46. Dietz W, Bandini L. \& Schoeller D. Estimates of metabolic rate in obese and nonobese adolescents. J Pediatr 1991; 118: 146-149.

47. Hofsteenge G, Chinapaw M, Delemarre-van de Waal H et al. Validation of predictive equations for resting energy expenditure in obese adolescents. Am J Clin Nutr. 2010; 91: 1244-1254.

48. Klein C, Villavicencio S, Schweitzer A et al. Energy Prediction Equations Are Inadequate for Obese Hispanic Youth. J Am Diet Assoc. 2011; 111: 1204-1210. 
49. Lazzer S, Patrizi A, De Col A et al. Prediction of basal metabolic rate in obese children and adolescents considering pubertal stages and anthropometric characteristics or body composition. Eur J Clin Nutr. 2014; 68: 695-699.

50. Marra M, Montagnese C, Sammarco R et al. Accuracy of predictive equations for estimating resting energy expenditure in obese adolescents. J Pediatr. 2015; 166: 1390-1396.

51. Molnár D, Jeges S, Erhardt E. et al. Measured and predicted resting metabolic rate in obese and nonobese adolescents. J Pediatr. 1995; 127: 571-577.

52. Schmelzle H, Schroder C, Armbrust S et al. Resting energy expenditure in obese children aged 4 to 15 years: Measured versus predicted data. Acta Paediatr. 2004; 93: 739-746.

53. Steinberg A, Manlhiot C, Cordeiro K et al. Determining the accuracy of predictive energy expenditure (PREE) equations in severely obese adolescents. Clin Nutr. 2017; 36: 1158-1164.

54. Harris J \& Benedict G. A biometric study of basal metabolism in man. Washington, DC: Carnegie Institute of Washington; 1919.

55. Henry CJK, Dyer S \& Ghusain-Choueiri A. New equations to estimate basal metabolic rate in children aged 10-15 years. Eur J Clin Nutr. 1999; 53: 134-142.

56. Henry CJK. Basal metabolic rate studies in humans: measurement and development of new equations. Public Health Nutr. 2005; 8: 1133-52.

57. Institute for Medicine of the National Academies, Food and Nutrition Board. Dietary reference intakes for energy, carbohydrate, fiber, fat, fatty acids, cholesterol, protein and amino acids. Washington DC: The National Academy Press; 2005.

58. Müller MJ, Bosy-Westphal A, Klaus S et al. World Health Organization equations have shortcomings for predicting resting energy expenditure in persons from a modern, affluent population: generation of a new reference standard from a retrospective analysis of a German database of resting energy expenditure. Am J Clin Nutr. 2004; 80: 1379-90.

59. Schofield WN. Predicting basal metabolic rate, new standards and review of previous work. Hum Nutr Clin Nutr. 1985; 39: 5-41.

60. World Health Organization (1985) Energy and protein requirements. Report of a Joint FAO/WHO/UNU Expert Consultation. World Health Organization Technical Report Series 724. http://www.fao.org/docrep/003/aa040e/AA040E00.htm\#TOC (accessed 28 March 2019). 
61. He F, Guan P, Liu Q et al. The relationship between obesity and body compositions with respect to the timing of puberty in Chongquing adolescents: a cross-sectional study. BMC Public Health. 2017; 17: 664 .

62. Solorzano CM \& McCartney CR. Obesity and the pubertal transition in girls and boys. Reproduction 2010; 140:399-401.

63. Li W, Deng QL, Chen Y et al. Association between Obesity and Puberty Timing: A systematic Review and Meta-Analysis. Int J Environ Res Public Health 2017; 14: 1266, doi:

10.3390/ijerph14101266

64. Department of Health \& Social Care (2011). Start active, stay active: report on physical activity in the UK.

https://assets.publishing.service.gov.uk/government/uploads/system/uploads/attachment_data/file/2 16370/dh_128210.pdf (accessed 20/05/19)

65. NHS Digital (2016). Health Survey for England 2015: Health, social care \& lifestyles. https://digital.nhs.uk/data-and-information/publications/statistical/health-survey-for-england/healthsurvey-for-england-2015 (accessed 13/05/19)

66. NHS Digital (2017) Health Survey for England 2016: Children's health. https://files.digital.nhs.uk/publication/m/c/hse2016-child-health.pdf (accessed 13/05/19)

67. McManus AM \& Mellecker RR. Physical activity and obese children. J Sport Health Sci 2012; 1: $141-148$.

68. Maffeis C. Total energy expenditure and patterns of activity in 8-10-year-old obese and nonobese children. J Pediatr Gastroenterol Nutr. 1996; 23: 256-61.

69. Goran MI. Physical activity related energy expenditure and fat mass in young children. Int J Obes Relat Metab Disord. 1997; 21: 171-8.

70. Maffeis C. Relationship between physical inactivity and adiposity in prepubertal boys. J Pediatr. 1997; 131:288-92.

71. Lazaar N, Aucouturier J, Ratel S et al. Effect of physical activity intervention on body composition in young children: influence of body mass index status and gender. Acta Paediatr. 2007; 96: 1315-1320. 
72. Skinner AC, Perrin EM, Moss LA et al. Cardiometabolic risks and Severity of Obesity in Children and Young Adults. NEJM. 2015; 373: 1307-1317.

73. Wells JCK. Energy Metabolism in infants and Children. Nutr. 1998; 14: 817-820.

74. Beggs MR, Garcia Guerra G \& Larsen BMK. Do PICU patients meet technical criteria for performing indirect calorimetry? Clin Nutr ESPEN. 2016; 15: 80-84.

75. Royal College of Paediatrics and Child Health (2019) UK-WHO growth charts 2-18 years. https://www.rcpch.ac.uk/resources/uk-who-growth-charts-2-18-years (accessed 28/11/19).

76. Centers for Disease Control and Prevention (2018) Defining childhood obesity. BMI for children and teens. https://www.cdc.gov/obesity/childhood/defining.html (accessed 28/11/19).

77. Zhang L, Chen R, Li R et al. Resting energy expenditure of obese children: a preliminary study. Chin J Clin Nutr. 2016; 24: 292-298.

78. Freitas Junior IF, Monteiro PA, Silveira LS et al. Resting heart rate as a predictor of metabolic dysfunctions in obese children and adolescents. BMC Pediatr. 2012: 12:5. doi: 10.1186/1471-2431$12-5$.

79. McDuffie JR, Adler-Wailes DC, Elberg J et al. Prediction equations for resting energy expenditure in overweight and normal-weight black and white children. Am J Clin Nutr. 2004; 80: $365-373$ 


\section{Table 1}

Studies evaluating prediction of resting energy expenditure in healthy overweight and obese children and adolescents included ${ }^{\mathrm{a}}$ in the systematic review.

\begin{tabular}{|c|c|c|c|}
\hline Authors (year) & Country and context of study & $\begin{array}{l}\text { Participants included in the quantitative synthesis } \\
\text { (number; sex; age; overweight/obesity category) }^{\mathrm{b}}\end{array}$ & $\begin{array}{l}\text { REE measurement (fast; conditions; equipment; } \\
\text { measurement duration) }\end{array}$ \\
\hline
\end{tabular}

\section{Derumeaux-Burel,}

Meyer, Morin and

Boirie $(2004)^{45}$

France, Clermont-Ferrand:

participants visiting a

paediatric nutritionist for the

first time

USA, Massachusetts and

Illinois: participants recruited

from weight control clinics
Cohort 1: 191 boys and 280 girls; 3-18 years; BMI zscore $\geq 2$

Cohort 2: 62 boys and 149 girls; 3-18 years; BMI zscore $\geq 2$
Overnight fast; monitored to prevent movement or sleeping; Deltatrac II; $\geq 45$ minutes measured (first 10 excluded)

Overnight fast; rested for 30 minutes; open circuit indirect calorimeter with ventilated hood; 30 minutes measured
Hofsteenge, Chinapaw, Netherlands, Amsterdam:

Delemarre-van de

Waal and Weijs

$(2010)^{47}$

Klein et al $(2011)^{48}$ participants recruited from a paediatric obesity outpatient clinic
Cohort 2: 13 girls; $15.1 \pm 1.5$ years (mean \pm standard

deviation); weight $\geq 120 \%$ ideal body weight

51 boys and 70 girls; $12-18$ years; overweight or obese according to Cole, Bellizzi, Flegal and Dietz (2000)
Overnight fast; supine and awake; Vmax Encore n29; 30 minutes measured (first 5 excluded)
USA, Washington, D.C: participants enrolled in a

weight loss trial
31 boys and 27 girls; $7-15$ years; $B M I \geq 95$ th percentile

Overnight fast (12 hours); rested for 20-30 minutes; Ultima CardiO2 system; 30 minutes measured (first 5 excluded) 


\begin{tabular}{|c|c|c|c|}
\hline Authors (year) & Country and context of study & $\begin{array}{l}\text { Participants included in the quantitative synthesis } \\
\text { (number; sex; age; overweight/obesity category) }^{b}\end{array}$ & $\begin{array}{l}\text { REE measurement (fast; conditions; equipment; } \\
\text { measurement duration) }\end{array}$ \\
\hline Lazzer et al $(2010)^{43}$ & $\begin{array}{l}\text { Italy; participants enrolled } \\
\text { before beginning a weight- } \\
\text { reduction programme }\end{array}$ & $\begin{array}{l}589 \text { boys and } 823 \text { girls; } 7-18 \text { years; BMI }>97 \text { th } \\
\text { percentile }\end{array}$ & $\begin{array}{l}\text { Overnight fast; supine and at rest; Vmax } 29 ; \geq 45 \\
\text { minutes measured (first } 10 \text { excluded) }\end{array}$ \\
\hline $\begin{array}{l}\text { Lazzer, Agosti, De Col } \\
\text { and Sartorio }(2006)^{23}\end{array}$ & $\begin{array}{l}\text { Italy; participants enrolled } \\
\text { before beginning a weight } \\
\text { reduction programme }\end{array}$ & $\begin{array}{l}\text { Group 2: } 19 \text { boys and } 34 \text { girls; } 12-18 \text { years; BMI > 99th } \\
\text { percentile }\end{array}$ & $\begin{array}{l}\text { Overnight fast; lying position; Vmax 29; } 30 \text { minutes } \\
\text { measured (first } 5-10 \text { excluded) }\end{array}$ \\
\hline $\begin{array}{l}\text { Lazzer, Agosti, De } \\
\text { Col, Mornati and } \\
\text { Sartorio }(2007)^{42}\end{array}$ & $\begin{array}{l}\text { Italy, Piancavallo: } \\
\text { participants recruited from the } \\
\text { Division of Auxology }\end{array}$ & $\begin{array}{l}121 \text { boys and } 166 \text { girls; } 7-18 \text { years; BMI }>97 \text { th } \\
\text { percentile }\end{array}$ & $\begin{array}{l}\text { Overnight fast; steady state achieved in lying } \\
\text { position; Vmax 29; } 30 \text { minutes measured (first 5-10 } \\
\text { excluded) }\end{array}$ \\
\hline $\begin{array}{l}\text { Lazzer, Patrizi, De } \\
\text { Col, Saezza and } \\
\text { Sartorio }(2014)^{49}\end{array}$ & $\begin{array}{l}\text { Italy, Piancavallo: } \\
\text { participants enrolled before } \\
\text { beginning a weight reduction } \\
\text { programme. }\end{array}$ & $\begin{array}{l}341 \text { boys and } 507 \text { girls; } 7-18 \text { years; } \mathrm{BMI}>97 \text { th } \\
\text { percentile }\end{array}$ & $\begin{array}{l}\text { Overnight fast; supine and at rest; Vmax } 29 ; \geq 45 \\
\text { minutes measured (first } 10 \text { excluded) }\end{array}$ \\
\hline
\end{tabular}

Marra et al (2015) $)^{50}$
Italy, Naples: measurements

performed before initiation of

a weight reduction

programme
109 boys and 155 girls; 14-18 years; BMI 30.0-70.0

$\mathrm{kg} / \mathrm{m}^{2}$
Overnight fast (12-14 hours); lying down, 15-minute adaptation period; Vmax29; 45 minutes measured 


\begin{tabular}{|c|c|c|c|}
\hline Authors (year) & Country and context of study & $\begin{array}{l}\text { Participants included in the quantitative synthesis } \\
\text { (number; sex; age; overweight/obesity category) }^{\mathrm{b}}\end{array}$ & $\begin{array}{l}\text { REE measurement (fast; conditions; equipment; } \\
\text { measurement duration) }\end{array}$ \\
\hline $\begin{array}{l}\text { Molnár, Jeges, Erhardt } \\
\text { and Schutz }(1995)^{51}\end{array}$ & $\begin{array}{l}\text { Hungary, Pecs: participants } \\
\text { referred to paediatric obesity } \\
\text { clinic }\end{array}$ & $\begin{array}{l}\text { Cohort } 1: 77 \text { boys and } 59 \text { girls; } 10-16 \text { years; body } \\
\text { weight } \geq 120 \% \text { expected weight for height } \\
\text { Cohort 2: } 49 \text { boys and } 30 \text { girls; } 10-16 \text { years; body } \\
\text { weight } \geq 120 \% \text { expected weight for height }\end{array}$ & $\begin{array}{l}\text { Overnight fast ( } 11 \text { hours); rested for } 30 \text { minutes; } \\
\text { Deltatrac indirect calorimeter; } 45 \text { minutes measured }\end{array}$ \\
\hline $\begin{array}{l}\text { Schmelzle, Schröder, } \\
\text { Armbrust, Unverzagt } \\
\text { and Fusch }(2004)^{52}\end{array}$ & $\begin{array}{l}\text { Germany, Greifswald: } \\
\text { participants admitted to } \\
\text { paediatric clinic }\end{array}$ & 49 boys and 33 girls; $4-15$ years; BMI >95th percentile & $\begin{array}{l}\text { Overnight fast ( } 12 \text { hours); rested for } 15-30 \text { minutes; } \\
\text { Detatrac II metabolic monitor; } \geq 30 \text { minutes } \\
\text { measured }\end{array}$ \\
\hline $\begin{array}{l}\text { Steinberg et al } \\
(2017)^{53}\end{array}$ & $\begin{array}{l}\text { Canada, Toronto. Participants } \\
\text { recruited from an outpatient } \\
\text { weight management clinic }\end{array}$ & $\begin{array}{l}84 \text { boys and } 142 \text { girls; } 12-18 \text { years; } B M I \geq 120 \% \text { of } 95 \text { th } \\
\text { percentile }\end{array}$ & $\begin{array}{l}\text { Overnight fast; rested, awake and supine; V-Max } \\
\text { Encore 29; 20-25 minutes measured }\end{array}$ \\
\hline $\begin{array}{l}\text { Tverskaya, Rising, } \\
\text { Brown and Lifshitz } \\
(1998)^{39}\end{array}$ & $\begin{array}{l}\text { USA, New York: paediatric } \\
\text { patients }\end{array}$ & 50 boys and 60 girls; $3-18$ years; BMI >28 & $\begin{array}{l}\text { Preprandial, early morning; resting awake state; } \\
\text { Deltatrac MBM-100 indirect calorimeter; } 30 \\
\text { minutes measured }\end{array}$ \\
\hline
\end{tabular}

\section{BMI - body mass index in $\mathrm{kg} / \mathrm{m}^{2}$}

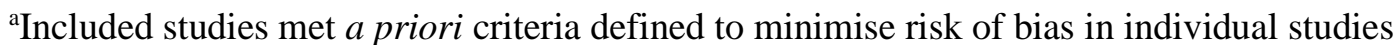

${ }^{\mathrm{b}}$ Overweight/obesity categories as described by authors 


\section{Table 2}

Prediction equations based on simple anthropometric and demographic variables evaluated for accuracy and precision by studies included in the systematic review

\begin{tabular}{|c|c|c|}
\hline Equation $^{\mathrm{a}}$ & Studies evaluating precision & $\begin{array}{l}\text { Studies evaluating } \\
\text { accuracy }\end{array}$ \\
\hline Harris \& Benedict (Harris and Benedict, 1919) ${ }^{54}$ & Hofsteenge et al $(2010)^{47}$ & Derumeaux-Burel et al $(2004)^{45}$ \\
\hline Male REE $(\mathrm{kcal})=66.4730+13.7516$ weight +5.0033 height $(\mathrm{cm})-6.7550$ age & Steinberg et al $(2017)^{53}$ & Hofsteenge et al $(2010)^{47}$ \\
\hline \multirow[t]{4}{*}{ Female REE $(\mathrm{kcal})=655.0955+9.5634$ weight +1.8496 height $(\mathrm{cm})-4.6756$ age } & & Lazzer et al $(2007)^{42}$ \\
\hline & & Schmelzle et al $(2004)^{52}$ \\
\hline & & Tverskaya et al $(1998)^{39}$ \\
\hline & & Steinberg et al $(2017)^{53}$ \\
\hline
\end{tabular}

Henry 1999 (Henry, Dyer and Ghusain-Choueiri, 1999) $)^{55}$

Male REE $(\mathrm{kJ})=66.9$ weight +2876

Female REE $(\mathrm{kJ})=47.9$ weight +3230
Hofsteenge et al (2010) $)^{47}$

Marra et al $(2015)^{50}$
Hofsteenge et al (2010) $)^{47}$

Marra et al $(2015)^{50}$
Henry 2005 (Henry, 2005) $)^{56}$

Male REE $(\mathrm{kcal})=18.4$ weight +581

Female REE $(\mathrm{kcal})=11.1$ weight +761

IOM healthy weight (Institute of Medicine, 2005) $)^{57}$

Male REE (kcal) 68 - 43.3 age +712 height +19.2 weight

Female REE $(\mathrm{kcal})=189-17.6$ age +625 height +7.9 weight
Hofsteenge et al (2010) $)^{47}$

Marra et al $(2015)^{50}$

Klein et al (2011) ${ }^{48}$

Steinberg et al $(2017)^{53}$
Hofsteenge et al (2010) ${ }^{47}$

Marra et al (2015) 50
Klein et al $(2011)^{48}$

Steinberg et al (2017) ${ }^{53}$ 


\section{Equation $^{\mathrm{a}}$
IOM overweight \& obese (Institute of Medicine, 2005$)^{57}$
Male REE $(\mathrm{kcal})=420-33.5$ age +418.9 height +16.7 weight}

Female REE $(\mathrm{kcal})=516-26.8$ age +347 height +12.4 weight

Lazzer (Lazzer et al, 2006) 23

REE $(k J)=54.96$ weight +1816.23 height +892.68 sex $^{b}-115.93$ age +1484.50
Studies evaluating precision

\section{Klein et al $(2011)^{48}$}

Steinberg et al (2017) 53

Hofsteenge et al (2010) $)^{47}$

Steinberg et al (2017) ${ }^{53}$

Hofsteenge et al $(2010)^{47}$

Lazzer et al $(2010)^{43}$

Steinberg et al (2017) ${ }^{53}$

Hofsteenge et al (2010) $)^{47}$

Marra et al (2015) $)^{50}$

Steinberg et al (2017) 53
Studies evaluating

accuracy

\section{Mifflin (Mifflin et al, 1990) 38 $^{38}$}

Female REE $(\mathrm{kcal})=9.99$ weight +6.25 height -4.92 age -161
Klein et al $(2011)^{48}$

Steinberg et al (2017) ${ }^{53}$
Molnár (Molnár et al, 1995) (1 $^{5}$

Male REE $(\mathrm{kJ})=50.9$ weight +25.3 height $(\mathrm{cm})-50.3$ age +26.9

Female REE $(\mathrm{kJ})=51.2$ weight +24.5 height $(\mathrm{cm})-207.5$ age +1629.8
Hofsteenge et al (2010) $)^{47}$

Lazzer et al (2006) ${ }^{23}$

Lazzer et al $(2007)^{42}$

Steinberg et al $(2017)^{53}$

Hofsteenge et al $(2010)^{47}$

Lazzer et al $(2010)^{43}$

Steinberg et al (2017) ${ }^{53}$

Hofsteenge et al (2010) ${ }^{47}$

Marra et al (2015) 50

Molnár et al (1995) 51

Steinberg et al (2017) ${ }^{53}$

Hofsteenge et al (2010) ${ }^{47}$

Molnár et al (1995) ${ }^{51}$

Hofsteenge et al (2010) ${ }^{47}$

Marra et al (2015) 50
Hofsteenge et al (2010) ${ }^{47}$

Marra et al $(2015)^{50}$
$\operatorname{REE}(\mathrm{MJ})=0.02606$ weight +0.04129 height $(\mathrm{cm})+0.311 \mathrm{sex}^{\mathrm{b}}-0.08369$ age -0.808 


\section{Equation $^{\mathrm{a}}$ \\ (Schmelzle et al, 2004)}

Male REE $(\mathrm{kcal})=6.6$ weight +13.1 height $(\mathrm{cm})-794$

Female REE $(\mathrm{kcal})=11.9$ weight +0.84 height $(\mathrm{cm})+579$

Schofield (Schofield, 1985) 59

Age 3-10

Male REE $(\mathrm{MJ})=0.082$ weight +0.545 height +1.736

Female REE $(\mathrm{MJ})=0.071$ weight +0.677 height +1.553

Age 10-18

Male REE $(\mathrm{MJ})=0.068$ weight +0.574 height +2.157

Female REE $(\mathrm{MJ})=0.035$ weight +1.948 height +0.837

\section{WHO weight \& height $^{\mathrm{d}}$ (World Health Organization, 1985) ${ }^{60}$}

Age 10-18

Male REE $(\mathrm{kcal})=16.6$ weight +77 height +572

Female REE $(\mathrm{kcal})=7.4$ weight +482 height +217
Studies evaluating

accuracy
Hofsteenge et al $(2010)^{47}$

Marra et al $(2015)^{50}$

Hofsteenge et al (2010) $)^{47}$

Marra et al (2015) $)^{50}$
Hofsteenge et al (2010) $)^{47}$

Marra et al (2015) 50
Derumeaux-Burel et al (2004) ${ }^{45}$

Hofsteenge et al (2010) ${ }^{47}$

Lazzer et al (2007) ${ }^{42}$

Marra et al (2015) 50

Schmelzle et al (2004) $)^{52}$

\section{Hofsteenge et al (2010) $)^{47}$}

Steinberg et al (2017) ${ }^{53}$
Derumeaux-Burel et al (2004) ${ }^{45}$

Dietz et al (1991) ${ }^{46}$

Hofsteenge et al (2010) $)^{47}$

Lazzer et al $(2007)^{42}$

Molnár et al (1995) 51

Steinberg et al (2017) ${ }^{53}$ 


\begin{tabular}{|c|c|c|}
\hline Equation $^{\mathrm{a}}$ & Studies evaluating precision & $\begin{array}{l}\text { Studies evaluating } \\
\text { accuracy }\end{array}$ \\
\hline WHO weight (World Health Organization, 1985) ${ }^{60}$ & Hofsteenge et al $(2010)^{47}$ & Dietz et al $(1991)^{46}$ \\
\hline Age 3-10 & Marra et al $(2015)^{50}$ & Hofsteenge et al $(2010)^{47}$ \\
\hline Male REE $(\mathrm{MJ})=95$ weight $+2071 / 1000$ & Steinberg et al $(2017)^{53}$ & Marra et al $(2015)^{50}$ \\
\hline Female REE $(\mathrm{MJ})=94$ weight $+2088 / 1000$ & & Molnár et al $(1995)^{51}$ \\
\hline Age $10-18$ & & Schmelzle et al $(2004)^{52}$ \\
\hline Male REE $(\mathrm{kcal})=17.5$ weight +651 & & Steinberg et al $(2017)^{53}$ \\
\hline Female REE $(\mathrm{kcal})=12.2$ weight +746 & & \\
\hline
\end{tabular}

REE, resting energy expenditure

${ }^{a}$ unless otherwise stated, weight in kilograms, height in metres, age in years

${ }^{\mathrm{b}}$ female $=0$, male $=1$

${ }^{c}$ male $=0$, female $=1$

${ }^{\mathrm{d}}$ WHO weight and height equation for age 10-18 also used in participants age 3-10 (no weight and height equation published for this age group) 


\section{Table 3}

Accuracy of equations predicting resting energy expenditure in three age groups, analysed by participant and by study subgroup

\begin{tabular}{|c|c|c|c|c|c|c|}
\hline \multirow{2}{*}{$\begin{array}{l}\text { Age } \\
\text { subgroup } \\
\text { (years) }\end{array}$} & \multicolumn{3}{|c|}{ Analysis by participants } & \multicolumn{3}{|c|}{ Analysis by study subgroup } \\
\hline & Equation & $\begin{array}{l}\text { Participants } \\
\text { (n) }\end{array}$ & $\begin{array}{l}\text { Bias } \\
(\%)\end{array}$ & Equation & $\begin{array}{l}\text { Subgroups } \\
(n)\end{array}$ & $\begin{array}{l}\text { Bias } \\
(\%)\end{array}$ \\
\hline \multirow[t]{14}{*}{$3-18$} & Müller & 385 & -13.9 & Müller & 3 & -14.0 \\
\hline & Mifflin & 1759 & -6.1 & IOM hw & 3 & -12.1 \\
\hline & Schmelzle & 385 & -4.3 & IOM oо & 3 & -11.9 \\
\hline & Molnár & 690 & -3.7 & Mifflin & 4 & -5.1 \\
\hline & Molnár single & 200 & -2.5 & Schmelzle & 3 & -4.5 \\
\hline & Harris \& Benedict & 1508 & -1.0 & Molnár & 6 & -4.1 \\
\hline & WHO wt \& ht & 2636 & 0.8 & Molnár single & 3 & -2.6 \\
\hline & Schofield & 1436 & 0.8 & Harris \& Benedict & 16 & -2.5 \\
\hline & Henry 1999 & 385 & 1.2 & Schofield & 13 & 0.4 \\
\hline & Henry 2005 & 385 & 2.2 & WHO wt \& ht & 13 & 1.3 \\
\hline & IOM hw & 284 & 3.0 & Henry 1999 & 3 & 1.7 \\
\hline & IOM oо & 284 & 4.5 & Henry 2005 & 3 & 3.4 \\
\hline & Lazzer & 687 & 5.2 & Lazzer & 5 & 3.7 \\
\hline & WHO wt & 970 & 9.2 & WHO wt & 10 & 8.7 \\
\hline \multirow[t]{14}{*}{$11-18$} & Müller & 385 & -13.9 & Müller & 3 & -14.0 \\
\hline & Schmelzle & 385 & -4.3 & Molnár & 4 & -4.7 \\
\hline & Molnár & 611 & -3.7 & Schmelzle & 3 & -4.5 \\
\hline & Mifflin & 347 & -2.4 & Mifflin & 2 & -2.9 \\
\hline & Molnár single & 121 & -2.0 & Molnár single & 1 & -2.0 \\
\hline & Schofield & 744 & 0.0 & Harris \& Benedict & 8 & -0.7 \\
\hline & Harris \& Benedict & 778 & 0.7 & WHO wt \& ht & 7 & -0.3 \\
\hline & WHO wt \& ht & 719 & 1.1 & Schofield & 7 & 0.5 \\
\hline & Henry 1999 & 385 & 1.2 & Henry 1999 & 3 & 1.7 \\
\hline & Henry 2005 & 385 & 2.2 & Henry 2005 & 3 & 3.4 \\
\hline & Lazzer & 400 & 7.6 & Lazzer & 4 & 4.2 \\
\hline & WHO wt & 624 & 9.2 & WHO wt & 5 & 8.8 \\
\hline & IOM hw & 226 & 9.4 & IOM hw & 1 & 9.4 \\
\hline & IOM oo & 226 & 11.6 & IOM oо & 1 & 11.6 \\
\hline \multirow[t]{3}{*}{$3-10$} & Harris \& Benedict & 166 & -3.6 & Harris \& Benedict & 4 & -4.8 \\
\hline & Schofield & 128 & 1.1 & Schofield & 2 & $\mathbf{0 . 0}$ \\
\hline & WHO wt & 128 & 9.2 & WHO wt & 2 & 8.4 \\
\hline
\end{tabular}

wt, weight; ht, height; hw, healthy weight; oo, overweight \& obese

Bias is the difference between mean measured resting energy expenditure (REE) and mean predicted REE expressed as a percentage of mean measured REE. The most accurate equation has the smallest magnitude bias. Negative bias indicates a tendency to underestimate REE. Positive bias indicates a tendency to overestimate REE. 


\section{Table 4}

Precision of equations predicting resting energy expenditure in two age groups, analysed by participant and by study subgroup

\begin{tabular}{|c|c|c|c|c|c|c|}
\hline \multirow{2}{*}{$\begin{array}{l}\text { Age } \\
\text { subgroup } \\
\text { (years) }\end{array}$} & \multicolumn{3}{|c|}{ Analysis by participant } & \multicolumn{3}{|c|}{ Analysis by study subgroup } \\
\hline & Equation & $\begin{array}{l}\text { Participants } \\
\text { (n) }\end{array}$ & $\begin{array}{l}\text { Precision } \\
(\%)\end{array}$ & Equation & $\begin{array}{l}\text { Subgroups } \\
(n)\end{array}$ & $\begin{array}{l}\text { Precision } \\
(\%)\end{array}$ \\
\hline \multirow[t]{13}{*}{$11-18$} & Mifflin & 347 & 62 & Mifflin & 2 & 63 \\
\hline & Schmelzle & 385 & 57 & Harris \& Benedict & 2 & 58 \\
\hline & Henry 1999 & 385 & 56 & Schmelzle & 3 & 57 \\
\hline & Harris \& Benedict & 347 & 54 & Henry 1999 & 3 & 56 \\
\hline & Molnár & 611 & 51 & Lazzer & 2 & 54 \\
\hline & Lazzer & 347 & 49 & Molnár & 4 & 52 \\
\hline & WHO wt \& ht & 347 & 45 & WHO wt \& ht & 2 & 47 \\
\hline & WHO wt & 611 & 44 & WHO wt & 4 & 46 \\
\hline & Schofield & 385 & 43 & Schofield & 3 & 43 \\
\hline & IOM hw & 226 & 41 & IOM hw & 1 & 41 \\
\hline & Müller & 385 & 35 & Müller & 3 & 36 \\
\hline & IOM oo & 226 & 34 & IOM oo & 1 & 34 \\
\hline & Henry 2005 & 385 & 29 & Henry 2005 & 3 & 32 \\
\hline \multirow[t]{13}{*}{$7-18^{a}$} & Schmelzle & 385 & 57 & Harris \& Benedict & 2 & 58 \\
\hline & Henry 1999 & 385 & 56 & Schmelzle & 3 & 57 \\
\hline & Harris \& Benedict & 347 & 54 & Henry 1999 & 3 & 56 \\
\hline & Molnár & 611 & 51 & Mifflin & 4 & 56 \\
\hline & Mifflin & 1759 & 51 & Lazzer & 2 & 54 \\
\hline & Lazzer & 347 & 49 & Molnár & 4 & 52 \\
\hline & WHO wt \& ht & 1759 & 44 & WHO wt & 4 & 46 \\
\hline & WHO wt & 611 & 44 & WHO wt \& ht & 4 & 45 \\
\hline & Schofield & 385 & 43 & Schofield & 3 & 43 \\
\hline & IOM hw & 284 & 37 & Müller & 3 & 36 \\
\hline & Müller & 385 & 35 & Henry 2005 & 3 & 32 \\
\hline & IOM oo & 284 & 33 & IOM oo & 3 & 32 \\
\hline & Henry 2005 & 385 & 29 & IOM hw & 3 & 28 \\
\hline
\end{tabular}

Precision expressed as percentage of participants with predicted resting energy expenditure

(REE) within $10 \%$ of measured REE; wt, weight; ht, height; hw, healthy weight; oo, overweight \& obese

${ }^{\text {a}}$ Data not available for children $<7$ years 


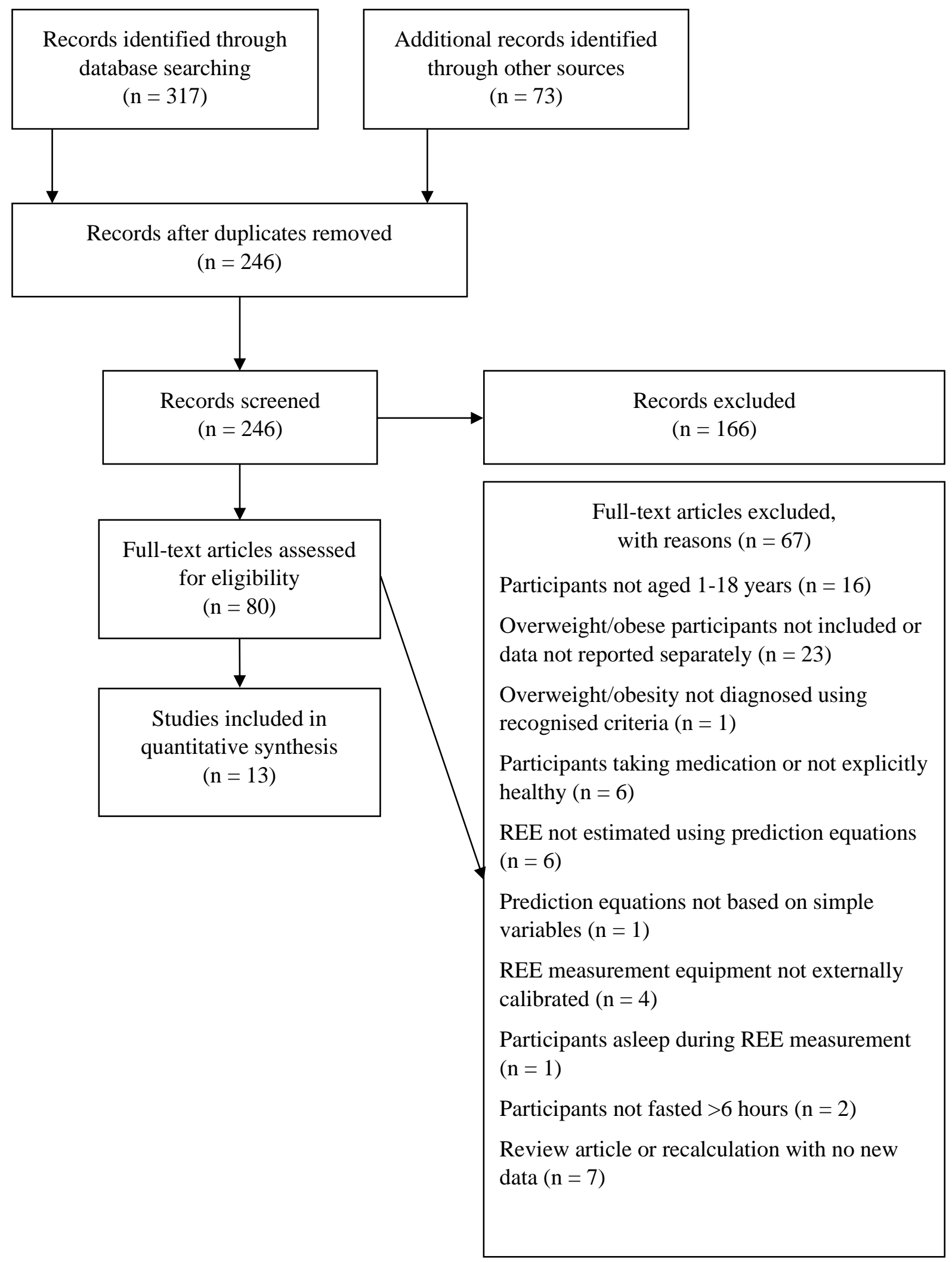

\section{Figure 1}

Flow and identification of studies for evaluation of equations predicting resting energy expenditure in overweight and obese children 